\title{
Assessing the influence of self-healing capacity of lime- based mortars on brick-mortar interface strength in masonry units
}

\author{
Cristina De Nardi ${ }^{1, *}$, Antonella Cecchi $^{1}$, and Liberato Ferrara ${ }^{2}$ \\ ${ }^{1}$ University IUAV di Venezia, DACC - Venezia, Italy \\ 2 Politecnico di Milano, DICA - Milano, Italy
}

\begin{abstract}
Among the materials used in constructions, self-healing ones have been widely studied, including polymers, asphalts, cement binders; nonetheless the issue of the implementations and engineering of the self-healing capacity of lime-based mortars has been seldom investigated. As a matter of fact, the aforementioned capacity in restoration of building heritage, as well as in concrete structures, would provide an interesting contribution in terms of durability of the same restoration work as well as of the building as a whole. The aim of this research is to study the influence of healing capacity on the masonry behaviour by means of shear tests. The choice to perform shear tests, with or without lateral precompression is due to the representativeness of conditions truly occurring in masonry structural elements when in service. "Triplet specimens" have been fabricated, consisting of 3 clay bricks and 2 layers of purposed-design mortar, to mimic the compositions of mortars which can be actually found in existing heritage buildings. The methodology envisages three phases: a first series of specimens, after 28 days curing in lab environment, was tested to evaluate the shear strength. Then, on a second series of samples, a damage was induced by loading them to a prescribed fraction $(70 \%)$ of the shear strength, determined as above in the previous stage; samples were subsequently immersed in water for 3 months and re-tested at the end of this curing period. Results clearly show that the autogenous healing capacity is responsible of an interesting recovery of the interface shear strength. The reliability of this approach has been also investigated by comparing the experimental results with a simplified FE model.
\end{abstract}

\section{Introduction}

In recent years, the use of lime-based mortars in restoration of cultural heritage has increased, also because of their chemical-physical and mechanical compatibility with old renders. As a matter of fact, the incompatibility of cement based mortars and ancient masonry has been clearly established due the presence or soluble salts, which can be dangerous to the original brick materials [1]. Lime mortar, instead, cannot be an efflorescence promoter, due to its relevant chemical purity [2]. Additionally, due to dissolution, transport and re-precipitation of calcium compounds, it can also have autogenous self-healing properties [3-5]. On one hand, the healing capacity might improve the strength of the mortar due to a nice combination of different mechanisms such as dissolution and re-precipitation of calcium compounds and further hydration of un-hydrated binder particles [3]. On other hand, the healing phenomena may also significantly increase the ductility of the mortar, influencing the mechanical behaviour of the whole masonry structure.
The aim of this work is to investigate the influence of autogenous healing capacity of lime-based mortars on the behaviour of brick-mortar interface in elementary masonry units. The idea is that the healing processes might affect the roughness of the crack surface as well as the adhesion by affecting the friction among the internal granules. The effectiveness of the self-healing capacity has been evaluated trough the recovery of brick-mortar interface shear strength by means of shear tests, performed on the so-called "triplet specimens", consisting of three bricks with two interposed mortar layers.

\section{Materials and Methods}

Several series of triplets, each consisting of 3 clay bricks and 2 layers of mortar were built. Physically, in case of bond failure occurring at the interface, the roughness of the brick elements is an important factor. In order to highlight the role of the mortar on the mechanical behaviour of the assembly, a limit case was studied, using a smooth type of bricks. 


\subsection{Brick properties}

Each brick has dimensions equal to $250 \times 120 \times 60 \mathrm{~mm}^{3}$, free water absorption equal to $10 \%$ by mass, dry density $1660 \mathrm{~kg} / \mathrm{m}^{3}$, compressive strength $18 \mathrm{MPa}$ and splitting strength equal to $2.2 \mathrm{MPa}$. Bricks were conditioned prior to laying by submerging them in water for 200 seconds.

\subsection{Mortar properties}

The employed mortar mix composition replicates as accurately as possible the one of lime mortars which can be found in heritage buildings, with the aim of likely use in retrofitting and restoration works [6].

The reference mortar is made of natural hydraulic lime (NHL5) with the addition of calcium hydroxide $\mathrm{Ca}(\mathrm{OH})_{2}$. The composition of the mortar and the chemical constituents of the lime are respectively listed in Tables 1 and 2.

Table 1. Chemical composition of the employed lime (percentages in weight related to original dry material).

\begin{tabular}{|c|c|}
\hline $\begin{array}{c}\text { Aggregates } \\
\text { NHL5 }\end{array}$ & \% \\
\hline $\mathrm{CaO}$ & 62 \\
\hline $\mathrm{MgO}$ & 1 \\
\hline $\mathrm{Al}_{2} \mathrm{O}_{3}$ & 5 \\
\hline $\mathrm{K}_{2} \mathrm{O}$ & 0,7 \\
\hline $\mathrm{Na}_{2} \mathrm{O}$ & 0,3 \\
\hline $\mathrm{Fe}_{2} \mathrm{O}_{3}$ & 3,5 \\
\hline $\mathrm{SiO}_{2}$ & 21 \\
\hline
\end{tabular}

Table 2. Mix design of the employed mortars (weight ratios).

\begin{tabular}{|l|c|}
\hline Constituent & Reference mortar \\
\hline $\begin{array}{l}\text { Slaked lime/dolomitic sand } \\
\text { ratio* }\end{array}$ & $1 / 3$ \\
\hline Water /lime ratio (w/c) & $0.221 / \mathrm{kg}$ \\
\hline $\mathrm{HHL} 5 / \mathrm{Ca}(\mathrm{OH})_{2}$ ratio & $1 / 1$ \\
\hline
\end{tabular}

* aggregate standard UNI EN 1015-1.

\subsection{Specimen types and preparations}

The specimens were built in accordance with the European Testing Standard EN 10523 [7].

In order to obtain the highest geometrical regularity (i.e. orthogonality of the faces), a jig was built and the thickness of mortar joint was fixed equal to $10 \mathrm{~mm}$.

Samples were cured under laboratory conditions at $\mathrm{T}=$ $23^{\circ} \mathrm{C} \pm 2^{\circ}$ and $\mathrm{RH} 50 \% \pm 4 \%$ for 28 days.

Shear tests were performed on the triplet specimens by applying a vertical load on the central brick at displacement ratio equal to $0.2 \mathrm{~mm} / \mathrm{min}$, while the outer ones were resting on a support. Half of the specimens were subjected to a transverse pre-compression force, applied through four threaded rods by a torque wrench and inducing a transverse confining stress equal to 0.6 $\mathrm{MPa}$. This force was held constant during the whole conditioning and testing period. The pressure was measured by the torque wrench as above, before and after the tests.

\subsection{Methods}

Three nominally identical specimens were tested per each case. A first series of triplets, cured under laboratory conditions, was tested in shear, with and without transverse normal stress, to determine the shear bond strength. A further testing campaign is actually ongoing, including the effects of several levels of transverse normal stress, complying with the aforementioned EN standard.

On a second series of samples, a damage was induced by loading them to a prescribed fraction (70\%) of the shear bond strength, determined as above. Samples were subsequently immersed in water for 3 months and re-tested at the end of the curing period. (Fig $1)$.

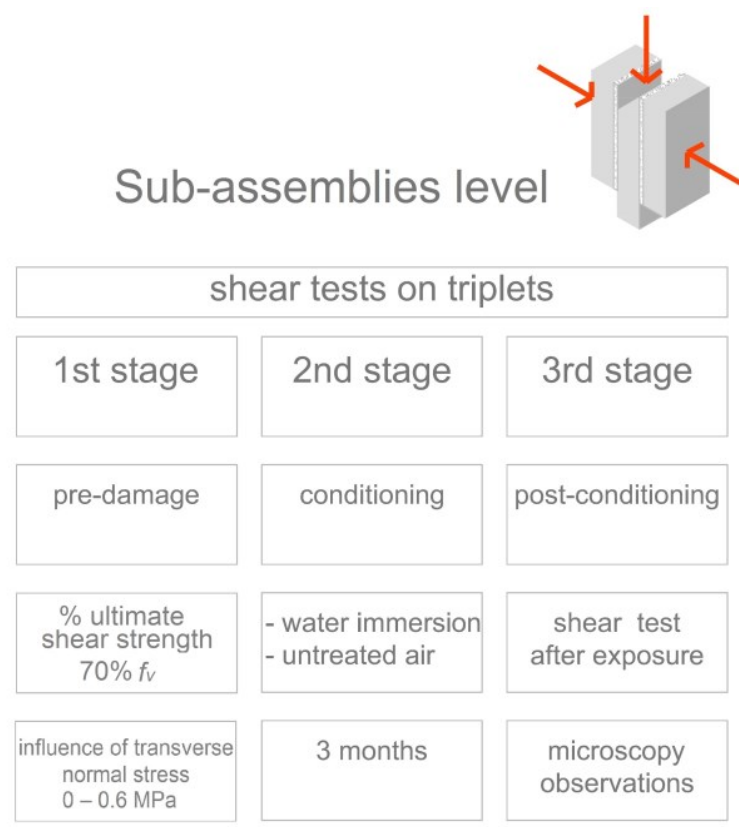

Fig. 1. Experimental programme: shear test performed on masonry sub-assemblies (triplets).

\section{Results and discussion}

All the tests, performed on samples made of clay brick and reference mortar joints, showed sliding failure modes. The results can be effectively interpreted by means of the Mohr-Coulomb failure criterion,

$$
f_{v}=f_{v 0}+\mu \sigma_{n}
$$


where $f_{v}$ is the shear strength; $f_{v 0}$, is the pure adhesion shear strength, i.e. with zero normal stress applied; $\mu$ is the friction coefficient [8-9].

In Table 3 the obtained Mohr Coulomb parameters are reported, with standard deviations in brackets.

Table 3. Cohesion and friction coefficient experimentally measured before and after healing on triplet specimens with joints made of reference mortar.

\begin{tabular}{|l|c|c|}
\hline Samples & $\mathbf{f}_{\mathbf{v} 0}[\mathbf{M P a}]$ & $\boldsymbol{\mu}$ \\
\hline $\begin{array}{l}\text { Undamaged_instantaneous } \\
\text { test }\end{array}$ & $0.19(0.07)$ & $0.29(0.14)$ \\
\hline $\begin{array}{l}\text { Undamaged_test after } 3 \\
\text { months in water }\end{array}$ & $0.41(0.08)$ & $0.20(0.13)$ \\
\hline $\begin{array}{l}\text { Pre-damaged_test after 3 } \\
\text { months in water }\end{array}$ & $0.35(0.12)$ & $0.57(0.16)$ \\
\hline
\end{tabular}

The water curing of the undamaged triplet specimens has determined an increase of shear strength, which has more than doubled along the investigated three months period. Anyway, the aforementioned prolonged water immersion has scantly affected the friction coefficient.

In samples in which a damage was induced by preloading at $70 \%$ of the shear strength, a remarkable recovery in both friction and cohesion parameters can be observed. Interestingly, the cohesion achieved about $85 \%$ of the value of companion undamaged samples cured in the same way, whereas a significantly higher friction coefficient was obtained. This could be explained through the favourable effect that a compressive stress normal to the mortar joint has likely had on the healing of the damage induced by the preshear. It can be reasonable assumed that the further hydration, together with the possibility of water to deeper penetrate into the mortar joints due to the induced damage, allow the healing processes to occur into the mortar matrix as well as into the brick-mortar interfaces.

As well-known in high calcium mortars, as the reference mortar herein employed, two types of $\mathrm{Ca}$ bearing compounds are present: $\mathrm{Ca}(\mathrm{OH})_{2}$ and $\mathrm{CaCO}_{3}$. In particular, the solubility of $\mathrm{Ca}(\mathrm{OH})_{2}$ is 100 times higher than that of $\mathrm{CaCO}_{3}$, so dissolution will be much easier. Water is responsible of its dissolution and transport to the damaged area. The subsequent re-precipitation of calcium compound fills the cracks and voids. As a matter of fact, thanks to healing processes - which can be summarized as dissolution, transport and recrystallisation of calcium compounds into voids and micro-cracks - the reconstruction of the trough-crack continuity of the mortar matrix has taken place, buildingup an enhanced load bearing capacity.

\subsection{First simplified FE model analysis}

Experimental tests have been reproduced with a finite element model (Strand7) assigning in input material parameters fitted on the experimental results. Masonry specimens have been modelled with quadrilateral finite elements in plane stress state. The adopted finite element mesh featured 25 elements along the depth, one element along each mortar joint thickness and 6 elements along each brick thickness.

\subsubsection{Loading, boundary conditions and FE governing parameters}

The loading has been applied as a displacement boundary condition, thus accurately reproducing the experimental tests, which were performed in displacement control procedure at a rate of $0.2 \mathrm{~mm} / \mathrm{min}$. The element simulating the two external bricks, have been restrained at bottom surface along both $\mathrm{X}$ and $\mathrm{Y}$ directions (nodes), while at the top surface of the central brick, along the Y direction, downward displacement has been applied (Fig. 2).

An elastic-plastic constitutive law has been adopted for the mortars material, together with a Mohr-Coulomb yield criterion, whereas brick material has been assumed as elastic. All the input parameter values are summarized in Table 4, as determined from experimental results; only Poisson's ratio has been estimated equal to 0.15 and 0.2 respectively for the mortar and the brick materials.

The acronyms M1,M2,M3, used in the Table below, is referred respectively to the reference mortar tested immediately at the end of the curing period (age 28 days); the reference mortar at age of 28 days, placed in water for 3 months; the reference mortar at the age of 28 , pre-damaged at $70 \%$ of its shear strength, after 3 months in water.

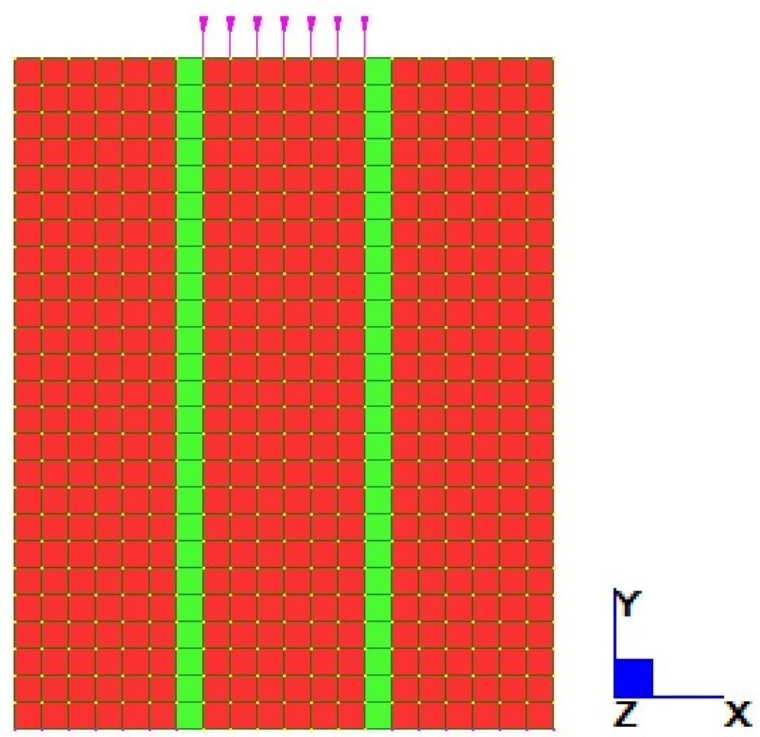

Fig. 2. FE model, geometry and boundary conditions

\subsubsection{Comparison with the experimental data: non-linear analysis}

As can be seen in Fig. 3, the experimental data of shear tests - performed on triplet specimens tested in three different condition: undamaged after 1 month (a), undamaged after 1 month in laboratory and 3 months of water immersion (b), pre-damaged (70\% shear strength) at 28 days and retested after 3 months of water immersion (c) - were compared with the results of a non 
linear analysis, solved by the use of the Finite Element model.

Table 4. FE model mortar governing parameters

\begin{tabular}{|l|c|c|c|}
\hline Mortar & M1 & M2 & M3 \\
\hline $\begin{array}{l}\text { Modulus of elasticity } \\
(\mathrm{Mpa})\end{array}$ & 1300 & 1600 & 1650 \\
\hline $\begin{array}{l}\text { Density }\left(\mathrm{kg} / \mathrm{mm}^{3}\right) \\
\text { MC criterion - cohesion } \\
(\mathrm{MPa})\end{array}$ & 1600 & 1600 & 1600 \\
\hline $\begin{array}{l}\text { MC criterion - friction } \\
\text { angle }\left({ }^{\circ}\right)\end{array}$ & 16 & 11.5 & 32 \\
\hline Brick & \multicolumn{3}{|c|}{ UNI - clay } \\
\hline $\begin{array}{l}\text { Modulus of elasticity } \\
(\text { Mpa) }\end{array}$ & \multicolumn{3}{|c|}{4500} \\
\hline Poisson's ratio & \multicolumn{3}{|c|}{0.2} \\
\hline Density (kg/mm $\left.{ }^{3}\right)$ & \multicolumn{3}{|c|}{1800} \\
\hline Elastic-criterion & \multicolumn{3}{|c|}{ Max stress } \\
\hline
\end{tabular}

The aforementioned comparison shows a good agreement, even if it is worth noting that while FE model adopts elasto-plastic law for the mortar, the experimental tests show, as usual, a highly brittle behaviour.

In particular, the data reported here appear to support the idea that the healing processes increase the deformation capacity of the assembly and thus resulting in a great peak strain than the starting one.

\section{Conclusion}

In this study, a methodology has been proposed to evaluate the influence of the healing capacity of lime mortars on the mechanical behaviour of masonry subassemblies (triplets), by means of brick-mortar interface shear tests. The methodology is based on inducing in the specimens a prescribed level of mechanical damage, then immersing the specimens in water, and, after scheduled immersion periods, testing them again until failure according to the same set-up used for pre-damaging.

All shear tests, performed on triplet specimens, showed sliding failure modes, which can be reliably interpreted by means of the Mohr-Coulomb failure criterion.

Shear tests performed on triplets allow the following remarks to be made:

- after 3 months in water immersion, undamaged specimens show an interesting increase of the shear strength, which is almost double than after one month curing in lab environment; the prolonged water immersion anyway scantily affects the friction coefficient.

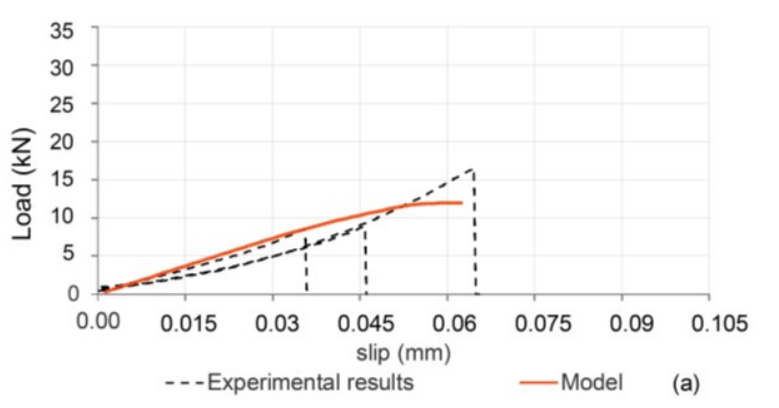

UNDAMAGED SAMPLES

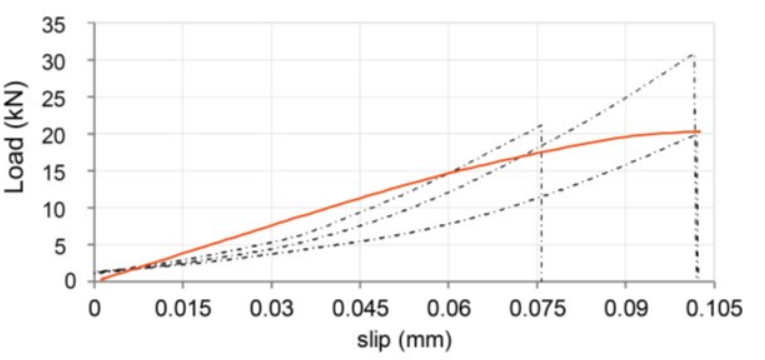

-..-Experimental results -Model (b)

UNDAMAGED SAMPLES AFTER 3 MONTHS WATER

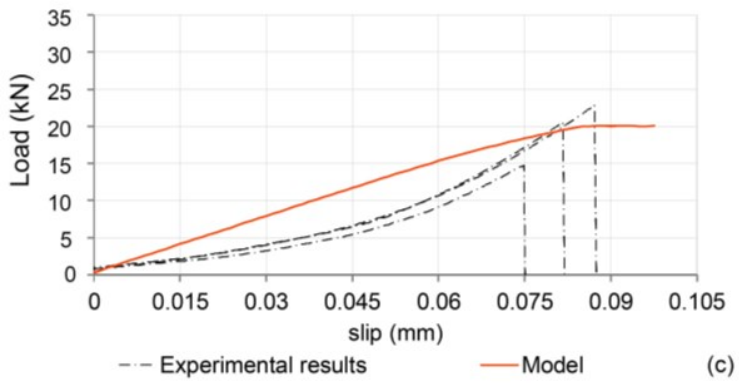

PRE-DAMAGED SAMPLES AT 70\%_AFTER 3 MONTHS WATER

Fig. 3. Comparison between experimental results and FE model.

- specimens pre-damaged at $70 \%$ of the shear strength, after 3 months in water, in dry conditions, show a remarkable gain in both friction coefficient and cohesion parameters.

As well-documented in recent researches, the autogenous healing phenomena, due to the recrystallization of calcium compounds, are able to produce compounds which fill void and micro-cracks. The increase of both cohesion values and friction coefficient is likely due to the migration of the calcium compounds from a part rich in lime to the brick-mortar interfaces. Thus, the processes of transport and reprecipitation of calcium materials may be responsible of the matrix through-crack continuity reconstruction and may build-up an enhanced mechanical capacity.

A first simplified FE model has been developed by using Strand7 computer code, in order to analyse the global behaviour and evaluate the mechanical parameters as well as the failure criterion. The experimental results appear to support the idea that the healing processes increase the deformation capacity of the investigated masonry subassemblies. 
Further tests will be performed on triplet specimens, with different levels of transverse normal stress - as indicated in the EN 1052-3 standard - with the aim to more closely align the experimental results in a $\sigma-\tau$ diagram and thus more accurately identify the MohrCoulomb criterion parameters. Also, further work will consider a more refined FE model, to better simulate the shear failure envelope for the joints + bond interface and the results of healing processes on the mechanical behaviour of the brick-mortar interfaces.

The authors wish to thank the technicians of Construction/Materials Science Laboratory (Labsco) University Iuav, for the support in performing experimental tests. The author also thank the School CPT (Schools of Civil Engineering of Padua), for having built the masonry subassemblies. The research has been carried out thanks to the financial support of PRIN 2015 (under grant 2015JW9NJT_014, project “Advanced mechanical modelling of new materials and structures for the solution of 2020 Horizon challenges"'). The financial support of University' IUAV di Venezia, Department of Architecture, Construction, Conservation is also gratefully acknowledged.

\section{References}

1. A. Moropoulou, K. Polikreti, V. Ruf e G. Deodatis, J Cult Herit, 4, 101-108 (2003).

2. Specification for lime and its uses in plastering, stucco. National Lime Association, Washington DC, 1966.
3. B. Lubelli, T. Nijland e R. van Hees, Self-healing of lime-based mortars: microscopyobservations on case studies, in 13th Euroseminar on Microscopy Applied to Building Materials, Ljubljana; Slovenia;, (2011).

4. De Nardi C, Cecchi A, Ferrara L, Benedetti A, Cristofori D. Composites Part B 124, 144-157. (2017).

5. C. De Nardi, S. Bullo S, L. Ferrara, L. Ronchin , A. Materials and Structures, (2017) 50:191 (2017).

6. F. Penas, Hydraulic lime mortars for wall rendering. Universidade Tecnica de Lisboa. Online, httpps://Fenix.tecnico.ulisboa.pt. (2008).

7. UNI EN 1.-3, «Metodi di prova per muratura: Determinazione iniziale a taglio,» (2007).

8. L. Binda, G. Mirabella, C. Tiraboschi and S. Abbaneo, Measuring masonry material properties, in D.P. Abrams and G.M. Calvi (eds), Proc. U.S.Italy Workshop on guidelines for seismic evaluation and rehabilitation of unreinforced masonry buildings, State Univ. of New York at Buffalo, NCEER-94-0021, 6-3/24, Pavia (1994).

9. R. van der Pluijm, Shear behaviour of bed joints, in Proceedings of the 6th North American Masonry Conference, Philadelphia, USA, 193 (2000). 